\title{
EDUCAÇÃO AMBIENTAL COM ENFOQUE NA PRESERVAÇÃO DA RESERVA BIOLÓGICA ESTADUAL DO AGUAÍ (SC)
}

\author{
Miram da Conceição Martins ${ }^{1}$ \\ Lia Cristiam Nascimento dos Santos ${ }^{2}$ \\ Carlos Henrique Devilla Marcello ${ }^{3}$ \\ Marta Valéria Guimarães de Souza Hoffmann ${ }^{4}$ \\ Paula Tramontim Pavei ${ }^{5}$
}

Resumo: A Educação Ambiental (EA) é um processo permanente, no qual os indivíduos e a sociedade se conscientizam da condição do seu ambiente e adquirem os conhecimentos que os tornam aptos a agirem individual e coletivamente. $\mathrm{Na}$ região sul de Santa Catarina, temos a Reserva Biológica Estadual do Aguaí (REBIO), Unidade de Conservação (UC) de proteção integral, fundamental para o abastecimento humano e função ecológica. O estudo objetivou possibilitar o envolvimento da comunidade escolar em ações de integração da Reserva Biológica Estadual do Aguaí no contexto educacional, desenvolvendo atividades pedagógicas com estudantes de ensino médio dos municípios de Nova Veneza, Siderópolis e Treviso (SC). Os estudantes mostraram seu protagonismo durante a participação no projeto.

Palavras-chave: Educação Ambiental; Reserva Biológica; Ensino Médio.

Abstract: The Environmental Education (EE) is a permanent process, in which people and society become aware of the condition of their environment and acquire knowledge, making them able to act individually and collectively. In the Southern Region of Santa Catarina, there is the Aguaí State Biological Reserve (REBIO), which is a Conservation Unit (CU) of integral protection, fundamental to community water supply, and ecological function. The study aimed to enable the involvement of the school community in actions to integrate the Aguaí State Biological Reserve in the education context, developing educational activities with high school students from the cities of Nova Veneza, Siderópolis and Treviso. The Students showed their role during their participation in the project.

Keywords: Environmental Education; Biological Reserve; High School.

\footnotetext{
${ }^{1}$ Universidade do Extremo Sul Catarinense. E-mail: mcm@unesc.net

2Universidade do Extremo Sul Catarinense. E-mail: lia-nascimento89@hotmail.com

3Universidade do Extremo Sul Catarinense. E-mail: carlosdevilla73@gmail.com

${ }^{4}$ Universidade do Extremo Sul Catarinense.E-mail: msh@unesc.net

${ }^{5}$ Universidade do Extremo Sul Catarinense. E-mail: ptp@unesc.net
}

Revbea, São Paulo, V.16, № 5: 547-565, 2021.

revista brasileira 


\section{Introdução}

O estado de Santa Catarina está inserido integralmente no bioma Mata Atlântica, abrigando uma ampla diversidade de plantas e animais e sendo privilegiado por dispor de Unidades de Conservação (UCs), dentre elas a Reserva Biológica Estadual do Aguaí (REBIO). O nome dessa reserva se deve à origem de uma árvore, popularmente chamada de Aguaí (Chrysophyllum viride Mart \& Eichler), espécie que apresenta grande riqueza na Unidade de Conservação (UC) e está presente na Floresta Atlântica (INSTITUTO FELINOS DO AGUAí, 2020).

A REBIO do Aguaí está inserida no bioma Mata Atlântica, que representa um dos mais ameaçados no mundo, sendo que, na América Latina, apenas $8 \%$ de sua área encontra-se em bom estado de conservação. Sua criação foi devida à riqueza de ecossistemas e à diversidade de espécies, além do seu relevo acidentado, tendo em vista que a Reserva se localiza no entorno da Serra Geral, com altitudes entre 200 e 1.470 metros, apresentando uma variedade de cânions (FATMA, 2020).

Com base na importância desta Unidade de Conservação, tanto para o abastecimento humano quanto por sua função ecológica, este projeto desenvolveu atividades de Educação Ambiental nas escolas próximas à Reserva do Aguaí, localizadas nos municípios de Treviso, Siderópolis e Nova Veneza, pertencentes à região carbonífera de Santa Catarina.

Nesse sentido, a Educação Ambiental (EA) se apresenta comprometida com a conscientização e participação da sociedade nos problemas socioambientais, propondo um olhar interdisciplinar para os conhecimentos nela tratados. Segundo Morin (2006, p.42), "como nossa educação nos ensinou a separar, compartimentar, isolar e não a unir os conhecimentos, o conjunto deles constitui um quebra-cabeças ininteligível'. O autor destaca que, quando se observa a história da Educação ou da Pedagogia, percebe-se que a maioria das pessoas foram educadas da mesma forma, de um modo rígido, fragmentado e autoritário, sem que compreendessem as ligações existentes entre os conhecimentos científicos e a sua própria cultura. A forma disciplinar que impera nas escolas gera conhecimentos limitados.

Portanto trabalhar EA em sala de aula não é papel fácil, pois muitos professores ainda não dão a devida importância ao tema ou até mesmo se sentem despreparados para isso (REIS-JÚNIOR, 2003). Neste contexto, a inserção de materiais didáticos nas aulas possibilita ao professor ter ferramentas que auxiliarão na discussão de ideias e pensamentos relacionados ao meio ambiente.

Freire (2005) nos lembra da importância de se tratar, nas escolas, das "contradições" em que vivem muitos de seus alunos, ou seja, trata-se nas escolas, por exemplo, de qualidade de vida, de saúde, de lazer, discute-se a beleza de algumas localidades, mas nos esquecemos, muitas vezes, conforme 0 autor, de perceber a realidade vivida por esses estudantes. Como vivem suas 
famílias? Onde moram? O bairro onde moram é limpo? Possui esgoto a céu aberto? É recoberto por pirita? Possui local de lazer para seus moradores?

Diante do exposto, este estudo tem como objetivo principal possibilitar o envolvimento da comunidade escolar em ações que visem à integração da Reserva Biológica Estadual do Aguaí no contexto educacional, buscando contribuir para o desenvolvimento de posturas compatíveis com a preservação e a conservação dos recursos naturais. Para isso, desenvolvemos atividades pedagógicas com estudantes de escolas públicas de ensino médio dos municípios de Nova Veneza, Siderópolis e Treviso (SC).

\section{Referencial Teórico}

A Floresta Atlântica era uma das mais largas florestas das Américas, abrangendo 17 estados brasileiros. Originalmente, cobria cerca de 150 milhões de hectares e ocupava $92 \%$ do litoral. Seu alcance é de, aproximadamente, $29^{\circ}$ de latitude, estendendo-se dos trópicos às regiões subtropicais (RIBEIRO et al., 2009).

Possuindo diferentes ecossistemas, a Floresta Atlântica é de grande importância, pois abriga uma parcela significativa da biodiversidade do Brasil e do mundo. Os altos níveis de riqueza e endemismo se devem à vasta distribuição latitudinal e conferem à floresta características edafoclimáticas variadas, favoráveis ao desenvolvimento de espécies endêmicas (MITTERMEIER et al., 2004).

A riqueza da Floresta Atlântica foi estimada por Myers et al. (2000) em 20 mil espécies de plantas vasculares, sendo 8 mil (40\%) endêmicas. Apesar do substantivo aumento do conhecimento acerca da flora da Floresta Atlântica, considera-se ainda insuficientemente conhecida, visto que em menos de duas décadas, mais de mil novas espécies de angiospermas foram descobertas, 0 que representa $42 \%$ do total descrito para o Brasil neste período (SOBRAL; STEHMANN, 2009).

O litoral de Santa Catarina apresenta uma extensa faixa de terras limitadas a leste pelas Serras do Mar e Geral, que seguem quase paralelas ao Oceano Atlântico, sendo, até o momento, a região mais preservada da Floresta Atlântica (RIBEIRO et al., 2009). Neste contexto, a população catarinense tem um grande desafio a ser enfrentado, pois muitos dos recursos básicos para a manutenção da vida humana estão diretamente ou indiretamente ligados a esses ambientes. Para o desenvolvimento de estratégias efetivas para a conservação, restauração e manejo sustentável da Floresta Atlântica, as perspectivas científicas devem ser integradas às necessidades sociais.

Uma das formas de possibilitar a preservação desses ambientes se dá por meio da criação de Unidades de Conservação (UCs). Na região sul de Santa Catarina, uma dessas áreas compreende a Reserva Biológica Estadual do Aguaí (REBIO), Unidade de Conservação de Proteção Integral criada pelo Decreto no 
19.635, de $1^{\circ}$ de julho de 1983, cuja gestão é responsabilidade da Fundação do Meio Ambiente (FATMA, 2020). Sua área é de aproximadamente 7.672 hectares e abrange o território dos municípios de Treviso, Siderópolis, Nova Veneza, Morro Grande e o entorno de Bom Jardim da Serra (FATMA, 2009).

Essa Unidade de Conservação de Proteção Integral contribui para a preservação de cabeceiras, riachos e rios da Bacia Hidrográfica do Rio Araranguá, sendo responsável por $46,3 \%$ da bacia que abastece a barragem do Rio São Bento, a qual, por sua vez, abastece toda a região carbonífera do sul catarinense. Também favorece a conectividade com outras Unidades de Conservação, destacando-se os Parques Nacionais de Aparados da Serra e Serra Geral, ao sul, o Parque Nacional de São Joaquim e o Parque Estadual da Serra Furada, ao norte. A Reserva Biológica Estadual do Aguaí contribui para a preservação de espécies vegetais ameaçadas de extinção, tendo grande importância na conservação da Mata Atlântica (FATMA, 2009).

De acordo com Simões (2008), as UCs protegem e regulam a quantidade e qualidade de água utilizada para o abastecimento da população, a estabilidade de encostas e promovem a manutenção da qualidade do ar, o que interfere de forma positiva na saúde das comunidades do entorno. Portanto a criação de uma UC é a melhor estratégia para a proteção dos recursos naturais de uma área, sendo que resulta na preservação da biodiversidade e dos recursos hídricos (FATMA, 2020).

Segundo Martins, Naspolini e Biz (2016), a escola avança as divisas de seus limites, afetando diretamente a vida de um grupo de pessoas muito maior do que aqueles que a frequentam. Por isso, ela deve garantir estudos sobre o ambiente onde vivem os estudantes, oportunizando que eles entrem em contato com questões da sua realidade. Desse modo "a inclusão da temática ambiental nos currículos escolares deve acontecer a partir de atividades diferenciadas, as quais possam conduzir os estudantes a serem agentes ativos no processo de formação de conceitos" (DIAS; SILVEIRA, 2020, p.50).

De acordo com a Proposta Curricular de Santa Catarina (PC/SC) (SANTA CATARINA, 1998), a função social da escola deve envolver o estudante com sua realidade, dando-lhe condições para que ele perceba o lugar que ocupa na natureza e na sociedade, possibilitando-os interferir nessa realidade por meio de ações coletivas que visem à melhoria da qualidade do ambiente no qual está inserido.

Esse envolvimento coletivo possibilita que aprendizados e experiências sejam compartilhados, buscando-se 0 enriquecimento intelectual, 0 desenvolvimento da cidadania e da autoestima, bem como um relacionamento ético com o ambiente. Portanto "nas escolas, a Educação Ambiental pode contribuir para a formação de cidadãos conscientes, aptos para decidirem e atuarem na realidade socioambiental' (DIAS; SILVEIRA, 2020, p. 47).

Considerada como um núcleo de intermediação entre os familiares dos alunos e a própria comunidade na qual está inserida (BRASIL, 2004), a escola 
extrapola as estreitas divisas de seus muros, afetando diretamente a vida de um grupo de pessoas muito maior do que o que a frequenta. Por isso ela deve garantir estudos sobre o ambiente em que vive o estudante, permitindo que ele entre em contato direto com o que está estudando.

A Educação Ambiental trata-se de um conceito, de grande importância, utilizado para designar ações voltadas às questões ambientais. A palavra "Educação" sugere uma troca de saberes, enquanto o termo "Ambiental" referese à percepção do meio e da interação do homem com a natureza (SEGURA, 2001). Interação essa que se materializa no ambiente, objeto de estudo da Educação Ambiental, no qual devem ser levados em consideração aspectos químicos, físicos e biológicos, incorporando relações socioeconômicas, culturais, políticas, ecológicas, éticas e estéticas (TELLES et al., 2002).

Tendo em vista, a conscientização para com o meio ambiente, a EA lança uma nova proposta de compreensão do mundo para valorização da ética e respeito às diversidades natural e cultural (SEGURA, 2001). Contribuindo, assim, para uma sociedade sustentável, por meio da aquisição de conhecimentos e habilidades, a partir dos quais são formadas atitudes que se transformam em práticas de cidadania (PHILIPPI; PELICONI, 2000). Além disso, sua missão é conscientizar a população sobre os efeitos causados pela poluição e quais as possíveis formas de prevenção, para que haja uma mudança no curso do histórico de degradação causada pela interferência do homem (SEGURA, 2001).

No âmbito escolar, a construção de uma nova sociedade implica em adotar uma postura crítica diante da realidade. Dessa forma, a EA compõe um conjunto de iniciativas que buscam reforçar a relação entre natureza e cultura (SEGURA, 2001), proporcionando a formação de indivíduos mais sensibilizados com as questões ambientais, instigando-os a uma nova racionalidade ambiental (MEDINA; SANTOS, 2000). Neste contexto, é importante que a EA venha a ser trabalhada nas escolas, visto que os estudantes se apresentam dispostos a explorar o conhecimento que lhes é mediado e, com isso, são preparados para diagnosticar problemas atuais e propor possíveis soluções (SILVA; MESQUITA; SOUZA, 2015).

Com o intuito de fazer com que a EA seja entendida e aplicada, de forma transversal e interdisciplinar, o presente estudo teve por objetivo ampliar 0 conhecimento dos estudantes sobre a REBIO do Aguaí, bem como promover ações de Educação Ambiental voltadas à preservação dessa. Desse modo, o estudo teve como foco realizar atividades pedagógicas capazes de instigar a percepção sobre a importância da preservação do meio ambiente e seus recursos naturais, nas escolas próximas à reserva, protagonizando os estudantes como mediadores desses novos conhecimentos.

As atividades pedagógicas propiciaram o desenvolvimento de atitudes, habilidades e valores para a construção de um ambiente com mais qualidade de vida, pois o ato de educar ambientalmente implica em mudanças de visão de mundo e no modo como nos relacionamos com ele. A escola é o lugar onde, de 
maneira mais sistemática e orientada, aprendemos a ler o mundo e a interagir com ele.

Considerando a abordagem das questões ambientais como um tema transversal, este estudo envolveu todas as áreas do conhecimento, promovendo na escola a articulação necessária entre a realidade escolar e o ambiente em que o estudante vive. Entende-se que as questões ambientais não podem ficar restritas às formas tradicionais de aquisição de conhecimento, por isso buscouse, nas diferentes áreas do conhecimento, a contribuição para uma educação que possibilite o ensino de atitudes e valores de cidadania.

O estudo desenvolvido, em seus pormenores, teve a participação efetiva dos docentes e discentes das escolas participantes, permitindo a realização de atividades pedagógicas envolvendo a escola e seu entorno, para que se percebesse que somos parte do ambiente e que temos responsabilidades perante o meio em que vivemos. Nesse processo de Educação Ambiental, devem estar presentes tanto a ação quanto a reflexão, tanto o pensar quanto o fazer, tanto a teoria quanto a prática, para que se dê a práxis, como afirma Goularte (2000), Freire (1998) e Silva (1986).

Uma proposta de Educação Ambiental não se determina por programas pré-estabelecidos nem se deixa guiar por livros didáticos. O conteúdo a ser trabalhado deve representar os problemas diagnosticados e, dessa maneira, as ações serão determinadas pela realidade ambiental do educando no sentido de transformá-la. Dessa forma, este estudo teve o propósito de propiciar uma experiência de educação para a sensibilidade ambiental, por meio da interação entre a Universidade (Unesc) e as escolas envolvidas. Foi um estudo interdisciplinar de educação para a sensibilidade ambiental e de ações visando a reeducar os sentidos sensoriais das pessoas que integram a comunidade escolar, no sentido de estimular atitudes e ações para cuidar, preservar e melhorar o ambiente de vida da escola e da comunidade.

Assim sendo, é notável a necessidade de estabelecer um pensamento em prol do meio ambiente, pois conforme esclarece Gumes (2005), o ser humano, atualmente, esbarra constantemente em meio a um universo de construções e reconstruções e está cada vez mais próximo de ações e reflexões responsáveis que findarão em uma conscientização ambiental.

\section{Procedimentos Metodológicos}

A pesquisa em EA não fica imune às turbulências da busca pelo novo paradigma, pois "a crise de paradigmas pela qual passa a produção científica nos últimos tempos exige reflexão sobre a crise de paradigmas nas ciências e na sociedade" (TOZONI-REIS, 2003, p. 13). É nesse contexto de busca por novos paradigmas que a EA vai se firmando enquanto campo de conhecimento e construindo sua prática, a fim de superar os limites e fragmentações que se encontram no bojo do conhecimento moderno. 
O estudo intitulado "Educação Ambiental com enfoque na preservação da Reserva Biológica Estadual do Aguaî" foi contemplado em edital da Universidade do Extremo Sul Catarinense (Unesc), que fica localizada no município de Criciúma, região sul de Santa Catarina. Trata-se de uma pesquisa qualitativa, exploratória, descritiva e de campo. A pesquisa qualitativa, de acordo com Lüdke e André (1986), realiza-se em seu ambiente natural como fonte direta dos dados, onde pesquisadores e participantes representativos da situação ou problema estão envolvidos de modo cooperativo ou participativo. Para tanto, foi levantada a seguinte questão: Qual a percepção dos estudantes com relação à Reserva Biológica Estadual do Aguaí?

Para concretização deste trabalho, foi realizada, inicialmente, pesquisa na literatura científica, especialmente artigos, dissertações e teses, a partir da base de dados encontrada no Periódicos Capes, Scielo, Bancos de Teses. Para o embasamento e elaboração das atividades pedagógicas, utilizou-se algumas obras literárias e artigos relacionados aos temas, além de materiais didáticos diferenciados obtidos no Laboratório de Ensino de Ciências (LEC) da Unesc.

A pesquisa aconteceu no período de 2018 a 2019, com quatro escolas estaduais situadas nos municípios de Nova Veneza (EEB Abílio Cesar Borges e EEB Humberto Hermes Hoffmann), Siderópolis (EEB José do Patrocínio) e Treviso (EEB Udo Deeke), situadas no sul de Santa Catarina. Foram envolvidos estudantes do ensino médio, da $1^{\text {a }}$ à $3^{\underline{a}}$ série, totalizando, durante o estudo, 244 estudantes com faixa etária de 15 a 20 anos.

As atividades desenvolvidas nas unidades escolares foram preparadas no Laboratório de Ensino de Ciências (LEC) da Unesc, seguindo o tema principal: Unidades de Conservação; e os secundários: Mata Atlântica, água, poluição atmosférica e bioindicadores.

Atividades desenvolvidas:

- "O que é uma reserva biológica?";

- Jogo da Memória Mata Atlântica;

- Jar-Test (equipamento utilizado no ensaio de floculação);

- Oficina - Terrário;

- Oficina - Mata ciliar;

- Teste de Ringelmann (Ferramenta utilizada na fiscalização relacionada à emissão de combustíveis fósseis);

- Jogo da poluição do ar - Tabuleiro;

- Bioindicadores, Teste de Micronúcleos (utilizados para verificar a poluição atmosférica causada por combustíveis fósseis); 
Antes de discutirmos o conceito e a importância da Reserva Biológica Estadual do Aguaí (REBIO), utilizando material didático elaborado no LEC da Unesc, perguntamos aos estudantes: "O que é uma reserva biológica?". $\mathrm{Na}$ sequência, cada um elaborou o conceito, suas respostas foram recolhidas, embaralhadas e distribuídas de forma aleatória para cada estudante da turma. Nessa etapa, foi realizada uma roda de conversa para socializar os conceitos elaborados, ocorrendo um debate. Posteriormente, apresentou-se o conceito de REBIO e sua importância, fazendo com que cada participante se apropriasse do tema.

O jogo da Mata Atlântica consistiu em um painel com placas ocultas que traziam as características de animais e plantas, dispostas para os estudantes. Os participantes escolhiam uma placa com características, liam as definições e tentavam descobrir qual era o animal ou planta correspondente. Antes do jogo, ocorreu uma roda de conversa sobre a Mata Atlântica, a fauna e a flora existentes, seu risco de extinção, sua importância e histórico.

Sobre o tema "água", desenvolvemos três atividades: inicialmente, uma exposição dialogada, discutindo a sua relação com a REBIO do Aguaí, já que é por meio dela que os vários municípios da região carbonífera recebem água para o abastecimento humano, agricultura e indústria. A primeira atividade foi a demonstração sobre o equipamento Jar-Test, em que se realizou um ensaio de floculação utilizando o referido aparelho.

As oficinas foram atividades nas quais os próprios estudantes montaram seus terrários, a fim de perceber, dessa forma, os ciclos biogeoquímicos, principalmente o ciclo da água, e foi construído um simulador de degradação do solo, mostrando a importância e a pertinência da mata ciliar para os rios e córregos.

Sobre o tema "poluição atmosférica", ocorreram três atividades: Teste de Ringelmann (atividade executada em ambiente externo), pois para ser realizado necessitava de veículos automotores movidos a combustível fóssil (diesel). O teste aconteceu de duas formas simultâneas, por meio do aplicativo virtual Ringelmann e da tabela de Ringelmann.

O jogo da poluição do ar consistiu em um tabuleiro no qual cada grupo teve a oportunidade de escolher um número e responder corretamente a uma pergunta relacionada com a poluição atmosférica e seu impacto sobre a REBIO do Aguaí, concedendo, assim, pontuação aos participantes pelos acertos.

Para o tema "bioindicadores", foi elaborada uma atividade prática de laboratório, na qual os estudantes observaram em microscópios óticos alterações em botões florais da planta Tradescantia pallida, resultante da poluição atmosférica, causadas por combustíveis fósseis e material particulado. 


\section{Resultados e Discussão}

Para discorrer sobre os resultados e discussão, é importante contextualizar a região onde aconteceu o estudo, ou seja, a Bacia Carbonífera Catarinense, que se encontra no sudeste do estado de Santa Catarina e abrange uma área de $1850 \mathrm{~km}^{2}$, ocupando uma faixa de $95 \mathrm{~km}$ de comprimento por 20 $\mathrm{km}$ de largura entre os paralelos $28^{\circ} 48^{\prime} 25^{\prime \prime}$ e $28^{\circ} 23^{\prime} 54^{\prime \prime}$ e meridianos $49^{\circ} 33^{\prime} 38^{\prime \prime}$ e 49015'11" (HORBACH et al., 1986; DNPM, 2008; MARTINS, 2014).

No sul do estado de Santa Catarina, a lavra mecanizada do carvão tem provocado alterações físicas, químicas e biológicas nos ecossistemas, comprometendo de forma direta os recursos hídricos, o ar, o solo e a biota, porquanto os impactos ambientais gerados são de grande magnitude.

Nesse cenário de degradação ambiental, temos a REBIO do Aguaí, fundamental para a manutenção dos rios do Sul Catarinense, pois mais da metade dos cursos d'água dessa região foram comprometidos pela exploração de carvão mineral e pela poluição. É importante salientar que alguns rios que abastecem a barragem do Rio São Bento nascem na REBIO, sendo que a UC também atribui um papel fundamental na recarga do Aquífero Guarani, um dos maiores reservatórios subterrâneos de água mundial (FATMA, 2020).

De acordo com Segura (2001), no ambiente escolar, os estudantes devem adotar uma postura crítica diante da realidade ambiental atual, para que seja possível a construção de uma nova sociedade, reforçando, assim, sua relação e cuidado com o ambiente natural. As atividades de EA proporcionam aos estudantes uma melhor compreensão do ambiente em que estão inseridos (CANTANHEDE et al., 2016).

O estudo aconteceu em quatro escolas públicas estaduais dos municípios de Nova Veneza, Siderópolis e Treviso, com as turmas diurnas do ensino médio, totalizando, no segundo semestre de 2018, 81 estudantes. No primeiro semestre de 2019, 105 escolares e, no segundo semestre do mesmo ano, 58 estudantes, com faixa etária de 15 a 20 anos.

A REBIO do Aguaí apresenta vasta biodiversidade, com relevante importância ecológica, além de oferecer recursos hídricos para a população dos municípios que residem próximos à ela. Nesse contexto, inicialmente, queríamos saber o nível de conhecimento que os estudantes de ensino médio tinham sobre a importância da REBIO do Aguaí e, para isso, lançamos a seguinte pergunta: "O que é uma reserva biológica?". Elencamos abaixo algumas respostas elaboradas pelos estudantes:

- "Lugar de preservação onde há proteção para a fauna e flora";

- " $\quad$ "Lugar que proporciona bem-estar e turismo ecológico";

- " "Lugar onde não há atividades humanas";

- "Lugar protegido por lei". 
É importante ressaltar que iniciamos nosso primeiro encontro nas escolas questionando os estudantes sobre a REBIO do Aguaí, e as respostas surgiram de modo espontâneo. Freire (1996) propõe que é preciso ter respeito pelos conhecimentos que os estudantes carregam e transmitem. Desse modo, "a Educação Ambiental constitui-se como uma estratégia para que se alcancem as mudanças desejadas na atual educação" (CUBA, 2010, p. 28).

Segundo Tuan (1980), a percepção é o resultado da interação da mente das pessoas, de suas atitudes e valores, experiências, expectativas, inteligência, valores éticos, morais e culturais, juntamente com os cinco sentidos, principalmente o da visão. Cada um de nós responde diferentemente aos estímulos e fatores do ambiente e, como consequência, também age sobre ele de modo distinto.

A EA vem intensificando a discussão das questões ambientais, numa vertente crítica, transformadora e emancipatória (CARVALHO, 2004; GUIMARÃES, 2006; MARCOMIN et al., 2017).

Vale ressaltar que, após a conclusão da atividade, organizamos uma roda de conversa com os estudantes, discutindo a importância da REBIO do Aguaí para a sustentabilidade da Região Carbonífera, discutindo sobre a interferência antrópica e chamando a atenção sobre a realidade da grande maioria dos nossos recursos hídricos, os quais estão comprometidos com metais pesados.

O jogo da Mata Atlântica consistiu em um painel com placas ocultas que traziam as características de animais e plantas, dispostas para os estudantes, do qual todos participaram com muito entusiasmo. Para Borges (2012), o material didático é indispensável no processo educativo e seu papel fundamental é o de contribuir para uma apropriação crítica do conhecimento por parte dos estudantes.

Segundo Calisto, Barbosa e Silva (2012), a aplicação de jogos educativos visa a melhorar o processo de aprendizado e a compreensão dos alunos diante do tema abordado. Por se tratar de um jogo, torna-se mais agradável, divertido e motivador. Com a aplicação do jogo da Mata Atlântica, foi perceptível a interação dos estudantes ao realizar a dinâmica, visto que eles não apresentaram dificuldades de identificar o vínculo entre as placas (Figura 1).

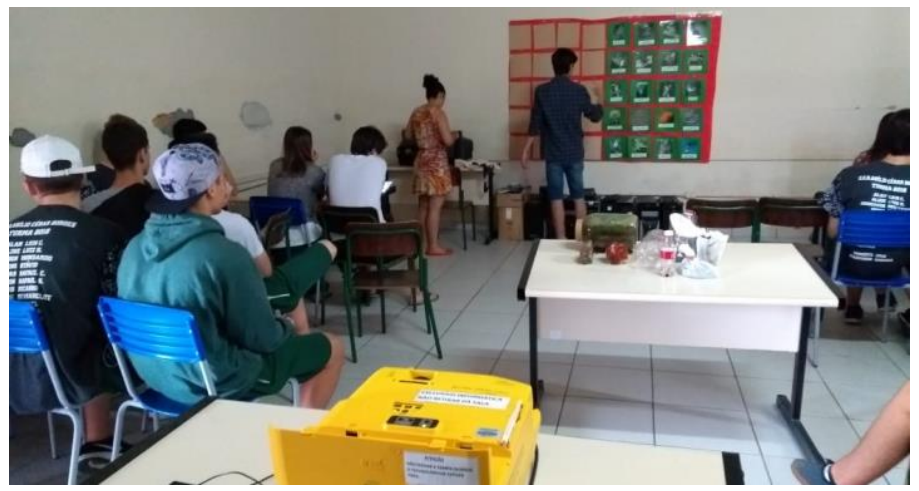

Figura 1: Aplicação do jogo da Mata Atlântica nas escolas envolvidas Fonte: dos autores, 2018. 
Correspondendo ao jogo da poluição atmosférica, foi possível perceber o trabalho em grupo entre os estudantes e o interesse de responder corretamente a cada pergunta. A aplicação dos jogos contextualizados com a realidade vivida oportuniza uma reflexão, pois, após conectadas e assimiladas as informações, o estudante pode ser capaz de compreender como cada ação individual pode ser importante para o meio ambiente (BREDA; PICANÇO, 2011).

Segundo Freitas (2013), é necessário que os professores criem estratégias para mostrar aos alunos que os conteúdos ensinados em sala de aula fazem parte de suas vidas e de seu dia a dia. Aproximando-se, dessa forma, do contexto no qual eles estão inseridos, por meio da utilização dos mais diversos recursos didáticos com fins pedagógicos.

Com relação às oficinas: construção de terrários e simuladores de mata ciliar - observou-se que os estudantes manifestaram interesse e entusiasmo, pois puderam colocar em prática o que aprenderam. De acordo com Lopes e Nunes (2010), a confecção de materiais didáticos em sala de aula resulta em diversas vantagens para a aprendizagem, pois, a partir dela, os estudantes aprendem de uma forma prazerosa.

Conforme Santos (2010), a partir do reconhecimento de jogos e oficinas como atividades pedagógicas, é possível criar condições para animar, despertar e alegrar os estudantes, percebendo os contextos de interação e riqueza que momentos podem proporcionar para o processo de ensino e aprendizagem.

De acordo com Oliveira e Toniosso (2014), compete ao professor a realização de práticas pedagógicas, vinculadas ao conceito de $E A$, na perspectiva de contribuir para a formação de pessoas com habilidades e atitudes voltadas à preservação do meio ambiente, tendo em vista o bem comum. "Sabese que é preciso criar estratégias de ensino que promovam engajamento e mobilização, bem como estimulem a reflexão e a capacidade crítica na busca por solução ou mitigação dos problemas ambientais" (DIAS; SILVEIRA, 2020, p. 47).

Percebeu-se que, ao levar materiais e equipamentos diferenciados com auxílio da tecnologia para desenvolver as atividades relacionadas aos recursos hídricos e poluição atmosférica, despertou-se a curiosidade nos estudantes.

Sendo assim, realizou-se a atividade desenvolvida com o aparelho JarTest (equipamento usado no ensaio de floculação), utilizado nas estações de tratamento de água e que faz as partículas finas de areia e argila presentes na água se juntarem, formando partículas maiores, facilitando sua purificação. Nessa atividade, demonstramos aos estudantes os passos realizados por uma estação de tratamento de água e como é necessária sua execução, ressaltando, ainda, os cuidados que todo cidadão deve exercer em relação à água que é um recurso básico e primordial a todo ser vivo.

Com a atividade proposta, foi possível discutir com os estudantes a importância das reservas e áreas naturais, devendo protegê-las para garantir qualidade de vida para as atuais e futuras gerações. Para autores como Dubow 
et al. (2011), a utilização de materiais didáticos facilita a compreensão dos estudantes sobre os fenômenos que ocorrem na natureza, tornando-se uma prática importante de EA.

É importante registrar que a Região Carbonífera de Santa Catarina, onde realizamos o estudo, é rica em recursos hídricos, porém apresenta a maioria de seus rios contaminados com metais pesados, sendo impróprios para consumo humano, agricultura e indústria, consequência da exploração e transporte de carvão mineral no século XX.

Ressaltamos que os estudantes participaram com muito interesse da atividade, pois conseguiram visualizar na prática como funciona uma estação de tratamento de água (Figura 2).

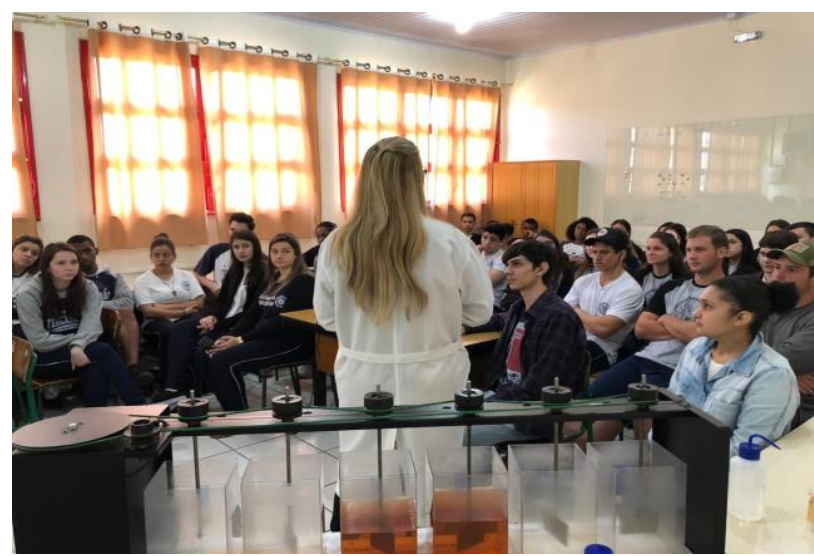

Figura 2: Realização da atividade prática utilizando o Jar-Test para os alunos compreenderem parte do processo do tratamento de água. Fonte: dos autores, 2019.

A poluição atmosférica é um tema que deve ser debatido nas aulas. Estudar o controle da emissão de poluentes é necessário para esclarecer aos jovens os efeitos que o excesso de gases e material particulado causam na atmosfera e as consequências que trazem para todas as formas de vida.

Uma ferramenta pedagógica para analisar a emissão dos gases resultantes de combustíveis fósseis dos automóveis é conhecida como Escala Ringelmann. Essa escala foi criada em 1890, pelo engenheiro francês Maximilian Ringelmann, e estabelece os padrões de emissão de poluentes aceitáveis para veículos movidos a diesel (LAFETÁ, 2019). Segundo o autor, o equipamento consiste em "uma lâmina de papel circular dividida em cinco partes, cada uma com uma tonalidade de cinza". A avaliação ocorre por comparação, sendo a tonalidade obtida na amostra comparada com uma das cinco tonalidades definidas, tendo, assim, um parâmetro de avaliação.

Com todo avanço tecnológico, foi instalado um aplicativo virtual Ringelmann nos dispositivos móveis (celulares) dos estudantes e, no dia da prática, para o teste de Ringelmann, utilizou-se uma placa branca, cartão índice de fumaça e aplicativo virtual Ringelmann, além dos veículos automotores movidos a diesel. O teste aconteceu de duas formas simultâneas: por meio do 
aplicativo virtual Ringelmann e da tabela de Ringelmann, em grupos, os estudantes realizaram a medição da fumaça dos veículos, anotando seus resultados. Posteriormente, os resultados foram discutidos e comparados entre as duas formas realizadas (Figura 3A e 3B).
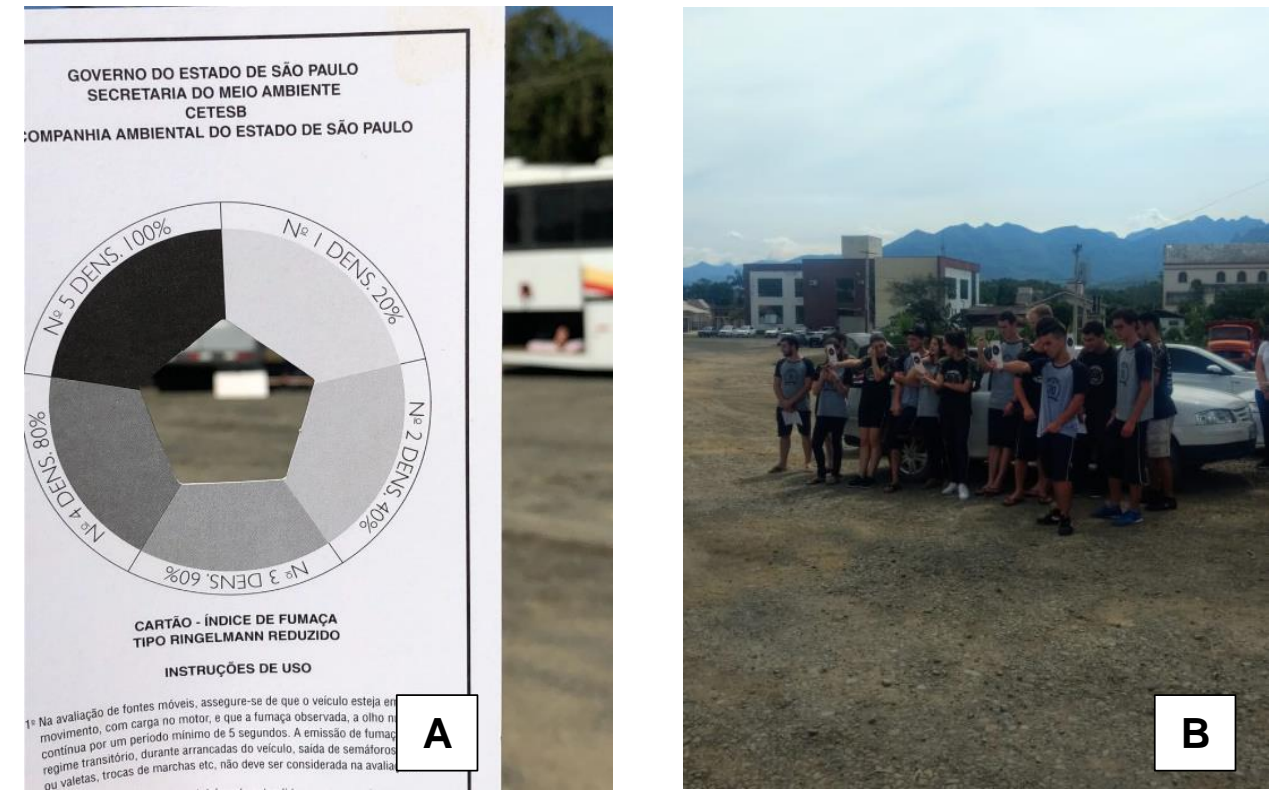

Figuras 3A e 3B: Figura A apresenta a escala de Ringelmann utilizada para realização do teste; Figura $\mathbf{B}$ retrata os alunos executando a atividade Teste de Ringelmann.

Fonte: dos autores, 2018.

Houve participação de todos os estudantes na atividade, os quais ficaram curiosos, se sentiram protagonistas ao utilizar um aplicativo no seu celular e fazerem uma avaliação dos gases emitidos por automóveis que utilizam combustíveis fósseis (diesel). Segundo Souza e Souza (2010), as ferramentas tecnológicas proporcionam 0 acesso a novos conhecimentos, facilitam a compreensão e o entendimento de temas a serem desenvolvidos em sala de aula.

A inserção das novas tecnologias da informação e da comunicação (NTICs) nas escolas é uma realidade; nossos estudantes estão conectados 24 horas por dia à internet, por meio de seus aparelhos eletrônicos, nos quais são bombardeados por novas informações que mudam sua forma de ver o mundo. Assim, cabe ao professor usar esse artifício a seu favor e não o tornar algo ruim aos olhos do ensino (PEREIRA; FREITAS, 2000).

Outra atividade desenvolvida com os estudantes foi a utilização da técnica de biomonitoramento com a Educação Ambiental, a qual permite a visualização direta dos danos provocados pela poluição atmosférica nas plantas. Com a introdução desse tema nos conteúdos escolares de forma diversificada, o assunto ministrado de forma diferente é incorporado ao dia a dia dos alunos (LUIZ et al., 2005). 
Utilizamos os botões florais do vegetal Tradescantia pallida (Rose) Hunt var. purpúrea, uma espécie muito comum, encontrada com facilidade em jardins e canteiros de várias cidades e desenvolvemos pesquisa com esse vegetal na Unesc.

A Tradescantia pallida é um bioindicador utilizado em estudos para analisar a qualidade do ar em ambientes urbanizados e alterados pela ação antrópica, pois ela absorve os poluentes e, durante o período da divisão celular da meiose de seus grãos de pólen, ocorre a mutação dos cromossomos, e como consequência a formação de micronúcleos. Essas estruturas são visíveis no microscópio, quando a célula está na fase de tétrade.

A atividade consistiu em verificar em lâminas de microscópio a presença de micronúcleos resultantes da mutação das células dos gametas da planta quando cultivadas em locais comprometidos com a poluição atmosférica, resultante de gases provenientes de materiais particulados e combustíveis fósseis (Figura 4).

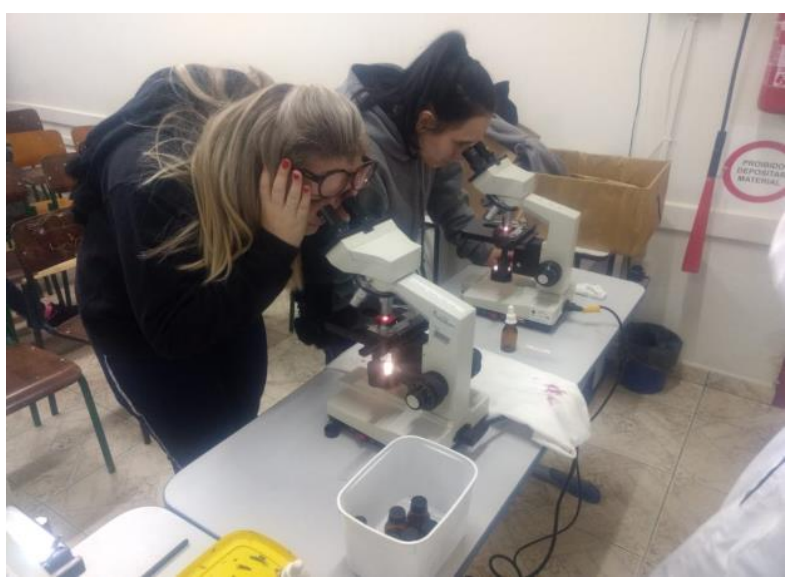

Figura 4: Atividade prática de microscopia analisando micronúcleos no botão floral da Tradescantia pallida. Fonte: dos autores, 2019.

Nesse sentido, Azinian (2004) descreve o uso da tecnologia como contribuição para o desenvolvimento de atividades e como facilita o trabalho com temas relevantes. Snyders (1988) argumenta que deve haver alegria ao experimentar e conhecer coisas diferentes do cotidiano. Verificamos, nos encontros, que os estudantes tinham curiosidade e interesse pelas atividades sugeridas durante o projeto.

Segundo Cardoso (2011), a EA tem papel fundamental na formação dos estudantes, visto que ela possibilita que o indivíduo se sinta inserido no meio ambiente em que vive, tornando-o consciente quanto ao cuidado que deve ter com ele. 


\section{Conclusões}

Por meio das atividades pedagógicas realizadas com os estudantes, foi possível fazer uma abordagem sobre Educação Ambiental de uma forma diferenciada, de modo que eles compreendessem as relações do homem com o meio ambiente. Todas as atividades realizadas aconteceram como previsto, sendo significativas e possibilitando alcançar os objetivos propostos. Os estudantes foram participativos, mostraram-se interessados em realizar as tarefas propostas, possibilitando o ato de educar ambientalmente e implicando em mudanças de visão de mundo e no modo como nos relacionamos com ele.

Desse modo, o desenvolvimento do estudo permitiu uma articulação com as escolas públicas estaduais dos municípios de Nova Veneza, Siderópolis e Treviso, aprendendo na prática temas relacionados à preservação da REBIO do Aguaí, correlacionando com os conteúdos ministrados em diferentes disciplinas de sua formação escolar. Assim, a EA corrobora com a reciprocidade dos estudantes para com o meio ambiente ao seu redor.

Esperamos ter conseguido promover a reflexão sobre a importância da REBIO do Aguaí, bem como de outras áreas com vegetação e espécies nativas, a fim de que os estudantes se conscientizem e espalhem esse conhecimento para as pessoas próximas, tornando-se multiplicadores ambientais.

Visando dar continuidade à questão ambiental evidenciada, é preciso que outras propostas sejam formuladas, com o objetivo de conhecer mais Unidades de Conservação presentes no estado e até mesmo fora dele. A participação das escolas nessa iniciativa é fundamental para o sucesso das atividades, pois nosso objetivo é tornar os estudantes protagonistas nesta caminhada.

\section{Agradecimentos}

À Universidade do Extremo Sul Catarinense (Unesc), PROACAD Diretoria de Extensão, Cultura e Ações Comunitárias - Edital no 101/2018, pelo apoio financeiro para o desenvolvimento do estudo.

\section{Referências}

AZINIAN, H. Integración de las tecnologías de la información y la comunicación em las práticas pedagógicas. Revista Novedades Educativas, Centro de Publicaciones Educativas y Material Didáctico S.R.L, Buenos Aires, v. 16, n. 168, 2004.

BORGES, G. L. A. Material didático no ensino de ciências. São Paulo: UNIVESP, 2012 . Disponível em http://acervodigital.unesp.br/handle/123456789/47362. Acesso em: 20 jun. 2020. 
BRASIL. Ministério da Educação. Secretaria de Educação Continuada, Alfabetização e Diversidade. Formando Com-Vida. Comissão do Meio Ambiente e Qualidade de Vida na Escola: Construindo Agenda 21 na Escola. Brasília, 2004.

BREDA, T. V.; PICANÇO, J. L. A Educação Ambiental a partir de jogos: aprendendo de forma prazerosa e espontânea. In: II SIMPÓSIO SOBRE EDUCAÇÃO AMBIENTAL E TRANSDISCIPLINARIDADE, 2011, Goiânia. Anais... $\quad$ NUPEAT, 2011. Disponível em: https://files.cercomp.ufg.br/weby/up/52/o/2 EDUCACAO AMBIENTAL com J $\underline{\mathrm{OG}}>$ Acesso em: 27 jun. 2020.

CALISTO, A.; BARBOSA, D.; SILVA, C. Uma análise comparativa entre jogos educativos visando a criação de um jogo para Educação Ambiental. In: BRAZILIAN SYMPOSIUM ON COMPUTERS IN EDUCATION (Simpósio Brasileiro de Informática na Educação - SBIE), out. 2012. Anais eletrônicos... Disponível em: https://www.br-ie.org/pub/index.php/sbie/article/view/1439. Acesso em: 27 jun. 2020.

CANTANHEDE, A. M. et al. Análise da percepção ambiental, por meio de desenhos, de alunos do ensino fundamental numa escola da zona rural, Chapadinha (MA). Revista da SBEnBio, Niterói, n. 9, 2016.

CARDOSO, K. M. M. Educação Ambiental nas escolas. 2011. 27 f. TCC (Licenciatura em Ciências Biológicas) - Universidade de Brasília, Brasília. Disponível em: https://bdm.unb.br/handle/10483/1892. Acesso em 25 de agosto de 2020.

CARVALHO, I. C. Educação Ambiental: a formação do sujeito ecológico. São Paulo: Cortez, 2004.

CUBA, M. A. Educação Ambiental nas escolas. ECCOM, v.1, n. 2, 2010. Disponível:

DEPARTAMENTO NACIONAL DE PRODUÇÃO MINERAL. Informe mineral: Desenvolvimento \& Economia Mineral. Brasília, DF: Publicações DNPM, 2008.

DIAS, M.S.S.; SILVEIRA, E.S.M. Educação Ambiental e a construção de percursos didáticos dialógicos no ensino médio. Revista Brasileira de Educação Ambiental, São Paulo, v15, n. 7, p.46-58, 2020.

DUBOW, M. et al. Material didático para o ensino das relações solo - água contaminação do ambiente. In: $31^{\circ}$ ENCONTRO DE DEBATES SOBRE O ENSINO DE QUÍMICA, 31., 2001, Rio Grande. Anais... Rio Grande: FURG, 2011. Disponível em: https://edeq.furg.br/noticias-e-avisos/24-31-edeq-anais. Acesso em 02 set. 2020.

FATMA. Reserva Biológica Estadual do Aguaí. Florianópolis: Fatma Disponível em: http://www.fatma.sc.gov.br/conteudo/reserva-biologica-estadualdo-aguai. Acesso em: 06 jun. 2020. 
FATMA. Reserva Biológica Estadual do Aguaí: plano de manejo. Florianópolis: Fatma, 2009. 174 p.

FREIRE, P. Educação como prática da liberdade. Rio de Janeiro: Paz e Terra, 1996.

FREIRE, P. Pedagogia da autonomia: saberes necessários à prática educativa. 7. ed. São Paulo: Paz e Terra, 1998.

FREIRE, P. Pedagogia do oprimido. 41. ed. Rio de Janeiro: Paz e Terra, 2005. FREITAS, A. C. O. Utilização de recursos visuais e audiovisuais como estratégia no ensino da biologia. 2013. 50 f. Monografia (Graduação em Ciências Biológicas) - Universidade Estadual do Ceará, 2013. Disponível em: http://www.uece.br/sate/dmdocuments/bio bbrbe o freitas.pdf. Acesso out.2020.

GOULARTE, M. L. M. A busca da compreensão do ambiente e de suas relações: um desafio para a educação. 2000. 90 f. Dissertação (Mestrado em Geografia) - Curso de Pós-Graduação em Geografia, Universidade Federal de Santa Catarina, 2000.

GUIMARÃES, M. Educação Ambiental: da forma à ação. Campinas, SP: Papirus, 2006.

GUMES, S. M. L. Construção da conscientização sócio-ambiental: formulações teóricas para o desenvolvimento de modelos de trabalho. Paidéia, Ribeirão Preto, v. 15, n. 32, 2005.

HORBACH, R. et al. Geologia. In: INSTITUTO BRASILEIRO DE GEOGRAFIA E ESTATÍSTICA. Levantamento de recursos naturais. 33. ed. Rio de Janeiro: IBGE; 1986.

INSTITUTO FELINOS DO AGUAÍ. Reserva Biológica Estadual do Aguaí. Disponível em: https://www.felinosdoaguai.com/unidade.htm. Acesso em 13 jul. 2020.

LAFETÁ, F. Escala Ringelmann ou Opacímetro: qual método devo utilizar? lus Natura [On-line], 29 jan. 2019. Disponível em: https://iusnatura.com.br/escalaringelmann-ou-opacimetro/. Acesso em: 15 Ago. 2020.

LOPES, F. M.; NUNES, A. N. Reutilização de materiais recicláveis para incentivo à Educação Ambiental e auxílio ao ensino didático de ciências em um colégio estadual de Anápolis-GO. Revista de Educação, v. 13, n. 15, 2010.

LÜDKE, M.; ANDRÉ, M. E. D. A pesquisa em educação: abordagens qualitativas. São Paulo: EPU, 1986.

LUIZ, E. J. et al. Sentindo a cidade: biomonitoramento da qualidade do ar de Santo André com plantas da espécie Tradescantia pallida e a Educação Ambiental. Secretaria Municipal de Saneamento Ambiental de Santo André. São Paulo: Semasa, 2005. 
MARCOMIN, F. E. et al. A Educação Ambiental e a percepção da paisagem. In: GIASSI, M. G., MARTINS, M. C.; SILVEIRA, Z. M. (orgs.). Práticas de ensino de ciências e Educação Ambiental. Curitiba: Multidiéia, 2017.

MARTINS, M. C.; NASPOLINI, N.; BIZ, L.; A Educação Ambiental. In: SANTOS, R. et al. (orgs.). Biodiversidade em Santa Catarina: Parque Estadual da Serra Furada. Criciúma, SC: Ediunesc, 2016.

MARTINS, M. C. Avaliação genotóxica em hortaliças cultivadas em áreas de exploração de carvão: potencial mutagênico e riscos à saúde humana. 2014. 119 f. Tese (Doutorado em Ciências da Saúde) - Curso de Pós-Graduação em Ciências da Saúde, Universidade do Extremo Sul Catarinense, 2014.

MEDINA, N. M.; SANTOS, E. C. Educação Ambiental: uma metodologia participativa de formação. Petrópolis: Vozes, 2000. 231 p.

MITTERMEIER, R. A. et al. Hotspots revisited: earth's biologically richest and most endangered terrestrial ecoregions. Washington, DC: Cemex, 2004.

MORIN, E. Os sete saberes necessários à educação do futuro. 11. ed. São Paulo: Cortez; Brasília, DF: UNESCO, 2006.

MYERS, N. et al. Biodiversity hotspots for conservation priorities. Nature, v. 403, p. 853-858, 2000.

OLIVEIRA, G. C. S; TONIOSSO, J. P. Educação Ambiental: práticas pedagógicas na educação infantil. Cadernos de Educação: Ensino e Sociedade, Bebedouro, SP, v. 1, n. 1, 2014.

PEREIRA, B.; FREITAS, M. $O$ uso das tecnologias da informação e comunicação na prática pedagógica da escola. Dia a Dia Educação [Portal], 2000.

em:http://www.diaadiaeducacao.pr.gov.br/portals/pde/arquivos/1381-8.pdf.

Acesso em: 15 jul de 2020.

PHILIPPI, J. A.; PELICIONI, M. C. F. Educação Ambiental: desenvolvimento de cursos e projetos. São Paulo: Signus, 2000.

REIS-JÚNIOR, A. M. A formação do professor e a Educação Ambiental. 2003. 194 f. Dissertação (Mestrado em Educação) - Curso de Pós-Graduação em Educação, Faculdade de Educação, Universidade Estadual de Campinas, São Paulo, 2003.

Disponível em: http://www.conexaoambiental.pr.gov.br/sites/conexaoambiental/arquivos restr. Acesso em: 10 ago. 2020.

RIBEIRO, M. C. et al. The Brazilian Atlantic Forest: How much is left, and how is the remaining forest distributed? Implications for conservation. Biological Conservation, v. 142, n. 6, 2009.

SANTA CATARINA. Decreto oㅜ 19.635, de 01 de julho de 1983. Cria a Reserva Biológica Estadual do Aguaí, e dá outras providências. Diário Oficial de Santa 
Catarina: seção 1, Florianópolis, 4 jul. 1983. Disponível em: https://bit.ly/39rQ6IA. Acesso em: 28 out. 2020.

SANTA CATARINA. Proposta Curricular de Santa Catarina: educação infantil, ensino fundamental e médio: disciplinas curriculares. Secretaria de Estado da Educação e do Desporto. Florianópolis: COGEN, 1998.

SANTOS, S. C. A importância do lúdico no processo ensino aprendizagem. 2010. 50 f. Monografia (Especialização em Gestão Educacional) - Universidade Federal de Santa Maria, UFSM, 2010.

SEGURA, D. S. B. Educação Ambiental na escola pública: da curiosidade ingênua à consciência crítica. Fundação de Amparo à Pesquisa do Estado de São Paulo. São Paulo: Annablume, 2001.

SILVA, A. C.; MESQUITA, G. M.; SOUZA, M. A. P. Educação Ambiental como paradigma para a construção da sustentabilidade. Revista Eletrônica em Gestão, Educação e Tecnologia Ambiental, Santa Maria, v. 19, n. 2, maio/ago. 2015.

SILVA, M. O. Refletindo a pesquisa participante. São Paulo: Cortez. 1986.

SIMÕES, L. L. Unidades de conservação: conservando a vida, os bens e os serviços ambientais. São Paulo, 2008. Disponível em:

http://www.mma.gov.br/estruturas/pda/ arquivos/prj mc 061 pub car 001 uc. pdf. Acesso em 12 jul. 2020.

SNYDERS, G. A alegria na escola. São Paulo: Manole, 1988.

SOBRAL, M.; STEHMANN, J. R. An analysis of new angiosperm species discoveries in Brazil (1990-2006). Taxon, v. 58, p. 227-232, 2009.

SOUZA, I. M. A; SOUZA, L. V. A. O uso da tecnologia como facilitadora da aprendizagem do aluno na escola. Revista Fórum Identidade Itabaiana: Gepiadde, a. 4, v. 8, jul./dez. 2010.

TELLES, M. Q. et al. Vivências integradas com o meio ambiente: práticas de Educação Ambiental para escolas, parques, praças e zoológicos. São Paulo: Sá, 2002.

TOZONI-REIS, M. F. C. Pesquisa em Educação Ambiental na universidade: produção de conhecimento e ação educativa. In:TALAMONI, J. L. B.; SAMPAIO, A. C. (orgs.). Educação Ambiental: da prática pedagógica à cidadania. São Paulo: Escrituras, 2003.

TUAN, Y.-F. Topofilia: um estudo de percepção, atitudes e valores do meio ambiente. São Paulo: DIFEL, 1980. 